\title{
Akıllı Ev Sistemleri Üzerine Bir Model Önerisi
}

Fatih ILKBAHAR, Düzce Üniversitesi, Yönetim Bilişim Sistemleri, Öğretim Görevlisi, fatihilkbahar@duzce.edu.tr, (D) 0000-0002-7964-3433

Şeyma ÜNAL, Düzce Üniversitesi, Yönetim Bilişim Sistemleri, Öğrenci, 1seymaunal@gmail.com, (iD) 0000-0003-4332-2037

Armağan Tuğçe KARAKAYA, Düzce Üniversitesi, Yönetim Bilişim Sistemleri, Öğrenci, atugcekarakaya@gmail.com, (D) 0000-0002-3080-0645

Bayram EREN, Düzce Üniversitesi, Yönetim Bilişim Sistemleri, Öğrenci, iletişim@bayrameren.net, (D) 0000-0003-4346-5556

$\ddot{O Z Z}$

Günümüzde, ev ve iş hayatın kolaylaştırmak amacıyla teknolojinin kullanımı her geçen gün yaygınlaşmaktadır. Sürekli gelişmekte ve değişmekte olan teknoloji ile akıllı ev kavramı ortaya çıkmıştır. Uzaktan yönetim ve güvenlik çözümleri uyguladıkça evlerimiz akıll duruma gelmektedir. Akıll duruma gelen evler bize zaman, güven, hız ve konfor kazandıran yaşam alanlarıdır. Bu yoğun yaşamda evden uzakta iken enerji israfina neden olan aletlerin uzaktan kontrol edilebiliyor olması, eve girişlerin denetlenebiliyor olması kullanıcılar için daha tasarruflu, daha güvenli ve daha konforlu bir yaşam sunmaktadır. Bu çalışmada, Telegram uygulaması üzerinden gönderilen kısa bir mesajla, prototip evde bulunan lambaların ve bahçe girişinde bulunan kameranın kontrolü gerçekleşmektedir. Buna ek olarak yüz tanıma sistemi ile eve giriş yapan kişinin yüzü algılanmakta ve sistem, ev sahibine giriş yapan kişinin bilgisini Telegram üzerinden bildirim olarak göndermektedir. Böylece eve girişte daha güvenli bir ortam oluşturulması amaçlanmaktadır.

Anahtar : Akıllı Ev, Telegram, Yapay Zekâ, Uzaktan Erişim/Kontrol

Kelimeler

\section{A Model Suggestion on Smart Home Systems}

ABSTRACT

Today, the use of technology is becoming widespread every day in order to facilitate home and business life. With the constantly developing and changing technology, the concept of smart home has emerged. Our homes become smarter as we implement remote management and security solutions. Smart homes are living spaces that give us time, confidence, speed and comfort. In this busy life, while being away from home, the devices that cause energy waste can be controlled remotely, and the entrance to the house can be controlled, providing a more economical, safer and more comfortable life for users. In this study, with a short message sent over the Telegram application, the lamps in the prototype house and the camera at the garden entrance are controlled. In addition, the face of the person entering the house is detected with the face recognition system and the system sends the information of the person who logs in to the host via Telegram as a notification. Thus, it is aimed to create a safer environment at the entrance to the house.

Keywords : $\quad$ Smart Home, Telegram, Artificial Intelligence, Remote Access/Control 


\section{EXTENDED ABSTRACT}

\section{Research Problem}

Nowadays, smart home systems are increasing in popularity with each passing day. Smart home systems have become an essential part of IoT applications. People use their smartphones, electronic devices, and electronic home appliances to remotely control them from anywhere on the internet. In this study, a smart home system model has been developed to make human life easier and safer. The main problem is that most electronic devices used in smart homes cannot be controlled remotely. This system was applied in the house, which was designed as a prototype. The purpose of this study is to provide easier control of electronic devices and to enable the user to control more than one home appliance remotely. It takes place in the proposed system using the Telegram application on any device with an Internet connection. In addition, the developed model offers solutions to energy efficiency, safety and ergonomics problems in electronic devices.

\section{Research Method}

The basic research method is used in the model proposed for smart home users. Additionally, after a prototype house was designed, the developed model was tested. The main problem was that users could not remotely control some electronic devices wirelessly. Communication was established between Telegram application and Raspberry Pi B + and Arduino (NodeMCU) boards to solve the basic problem. In order for electronic devices to communicate with the user, predefined scripts must be run. As an example of the command sequences, the lamps and the camera in the house can be controlled easily. The communication of simple special expressions that the users wrote in daily language on the chat screen in the Telegram application was provided with electronic cards. The protocols written for this communication are the script language and the Telegram Bot API. Thus, the user can easily control the modules (lamps, camera control modules) inside the house, even if they are inside or outside the house. In addition, the face recognition system has been tested using the LBP (Local Binary Pattern) algorithm in face recognition systems. The developed model was designed separately in Visual $\mathrm{C}++$ and Python languages and tested by users using the openCV image processing library.

\section{Result}

Thanks to the developing technology, communication between electronic devices is getting easier. Users are enabled to control electronic devices more easily. Thanks to the control of electronic devices, a safer and more comfortable living standard is aimed. In line with this purpose, the smart home systems prototype developed was provided by controlling using the same system as software and hardware. With the developed system, users can 
control the lamp or camera in the house, even if they are away from their homes, thanks to the simple commands specified in the chat section of the Telegram application. When necessary, feedback is received from electronic cards. Studies and experiments on the application have determined that users can both save energy and live in a safer environment.

\section{GİRIŞ}

Akıllı ev kavramı; ev sakinlerinin ihtiyaçlarını karşılayabilen, hayatlarını kolaylaştırabilen, geleneksel evlere nazaran daha emniyetli, daha konforlu olmasıyla beraber kaynakları daha ekonomik kullanılarak insanlara kaliteli bir yaşam sunabilen evleri tanımlamak için kullanılmaktadır. 1980'li yıllarda ilk defa akıllı ev kavramı olarak adından söz edilmeye başlanmıştır. Akıllı evlerin içermiş olduğu cihazlar, o sistemleri ve fonksiyonları kullanan kullanıcıların kontrol edebileceği cihazlardır (Stefanov vd., 2004). Günümüzde, akıllı ev sistemleri her geçen gün popülaritesini arttırmakta ve hızlı bir şekilde hayatımıza entegre olmaya devam etmektedir. Bu çalışmada, insan yaşamını daha kolay ve güvenli bir duruma getirebilmek amacıyla bir akıllı ev sistemi geliştirilmiş ve prototip ev üzerinde bu sistem uygulanmıştır.

$\mathrm{Bu}$ çalışmanın amacı, kullanıcının cep telefonu, bilgisayar, tablet ya da internet bağlantısı olan herhangi bir cihaz üzerinden Telegram uygulamasını kullanarak, birden fazla ev aletini uzaktan kontrol etmesini ve izlemesini sağlayan bir sistem geliştirmektir. Önerilen bu sistem, kullanıcılara her zaman enerji tasarrufu, konfor ve güvenlik sağlayan bir araç olacaktir.

Akıllı ev sistemleri artık nesnelerin interneti yani IoT uygulamalarının önemli bir parçası durumuna gelmiştir. İnsanlar akıllı telefonlarını, cihazlarını ve ev aletlerini internet aracılığıyla her yerden uzaktan kontrol etmek için kullanmaktadır. Cihazları akıllı telefonla kontrol etmenin çeşitli yolları vardır. Bu projede, akıllı telefondan evdeki cihazları kontrol etmek için Google asistan servisi ile Arduino bağlantısı sağlanmıştır. Başka bir şekilde de NodeMCU kullanarak Telegram uygulamasından kısa mesajla lamba kontrol edilmiştir. Buna ek olarak, akıllı ev girişinde güvenliği sağlayabilmek için Raspberry Pi Kamera modülü kullanılarak yüz tanımaya ilişkin çalışmalar gerçekleştirilmiştir. Projenin yazılımsal kısmında programlama dili olarak C++, donanım kısmında ise Arduino ve Raspberry Pi kullanılmıştır. Arduino'ya ek olarak Raspberry Pi kullanılma nedeni, prototip evin voltajına Arduino' nun tek başına yeterli olmamasıdır.

$\mathrm{Bu}$ sistem ile kullanıcılar, Telegram uygulaması üzerinden verdiği komutla, ev içerisinde belli teknolojik aletlerin açılıp kapanmasını uzaktan erişim ile sağlayabilmektedir. Kamera ile yüz tanıma yöntemi kullanılarak eve giriş yapan kişinin isim bilgisi Telegram uygulaması üzerinden kullanıcıya bildirilmektedir. Ayrıca kullanıcı istediği an Telegram üzerinden verdiği komutla birlikte evin dış görüntüsüne ulaşabilmektedir. Telegram uygulamasının günümüzde kullanıcılar tarafından popüler bir duruma gelmesi ve birçok uygulama ile entegre bir şekilde çalışıyor olması geliştirilen akıllı ev sisteminde bu 
uygulamanın kullanılmasının başlıca sebebidir. Telegram uygulaması, içinde barındırdığı uygulama programlama arayüzü API (Application Programming Interface)'ler sayesinde sistemi geliştirirken, yazılımsal olarak iş yükünü de hafifletmiştir.

Telegram, akıllı ev sistemini kullanan ev sahiplerinin, uygulama üzerinden bir grup oluşturarak ev hanesindeki herkesin sistemi yönetebilmesi konforuna olanak sağlamaktadır. Konfor sağlamanın yanında, Telegram sunduğu sesli komut özelliği ile engelli insanların da evlerine uzaktan erişebilmesini sağlamaktadır. Bu sesli komut özelliği algıladığı sesi yazıya çevirerek, verilen komutu algılayıp işlemi istenilen şekilde gerçekleştirmektedir.

$\mathrm{Bu}$ makalenin giriş kısmında akıllı ev kavramı tanımlanmış, akıllı evlerin insan yaşamındaki yerinden bahsedilmiş, çalışmanın amacı, çalışmada kullanılan algoritma ve yöntemler belirtilmiştir. Çalışmanın sonraki kısımlarında, akıllı ev sistemleriyle ilgili geçmişte yapılan çalışmalar kapsamlı bir şekilde incelenerek sunulmuştur. Önerilen model için kullanılan algoritma ve yöntemler daha detaylı bir şekilde incelenerek sistemin genel yapısı hakkında bilgiler verilmiştir. Sonuç bölümünde ise önerilen modelde uygulanan yöntemlerin başarısının ve mevcut durumun analizi yapılarak projenin geleceği ve ilerlemeler hakkında fikirler üretilmiştir.

\section{GEÇMIŞTEKI ÇALIŞMALAR}

Akıllı ev terimi, bazı sistemlerle donatılmış evleri veya bu sistemlere sahip olan binaları, yapıları açıklamak amacıyla kullanılır. Bu terim tasarlanan akıllı uygulamaların eyleme geçmesiyle anlam kazanır (Yiqin vd., 2009). Tasarımı ve işletimi akıllı olacak şekilde tasarlanmış yapılar hem yönetim konusunda hem de etkinlik ve verimlilikte getirim oluşturmaktadır. Akıllı ev sistemleri genel olarak ele alındığında, bu sistemlerin başlıca amacının insan yaşamını kolaylaştırmak olduğu açık bir şekilde ifade edilebilir (Li Jiang vd., 2004).

Bu bölümde geçmişteki çalışmaların bazılarında kullanılan yöntemler kısa bir şekilde özetlenmektedir.

IoT kavramı, etrafımızda gelişen hareketleri kontrol mekanizmalarıyla yönetebilmemize, hareketleri izleyerek çözümleyebilmemize imkân sunar. IoT, cihaz ve yazılımlar kullanılarak fiziksel objelerin kendi aralarında veya daha büyük düzeneklerle irtibat halinde olduğu bir iletişim ağıdır (Gökrem ve Bozuklu, 2016). Bu tür ağlar, evlerimizdeki en küçük aletlerden akıllı kentlere uzanır duruma gelmiştir. Etkili ve yaratıcı bir IoT projesi oluşturulabilmesi amacıyla bu teknolojiye ayak uydurabilen bazı mikrodenetleyiciler kullanılmaktadır (Başçiftçi ve Gündüz, 2019).

Yaşanabilecek salgın hastalıklara karşı salgının yavaş ilerlemesi için akıllı evler kullanılarak, hastalıkla ilgili yapay zekâ teknolojilerinin avantajları sunulmuştur. İnsanların 
daha sağlıklı olabilmeleri için gereken önlemlerin alınmasının sağlanabilmesi önerilmiştir (İlkbahar ve Sungu, 2020).

Yapılan bu çalışmanın donanım bölümünde, NodeMCU kullanılmıştır. NodeMCU kullanılmasının sebebi bu tarz IoT özelliğine sahip olan tasarımların prototiplenmesine yardımcı olmasıdır. Programlanabiliyor olması nedeniyle de daha az maliyet ile gerçekleştirilme olanağı sağlar (Taştan, 2019). Bununla birlikte Ardino tarzında geliştirme kartına ihtiyaç duymaz, mikro usb kullanılarak kolay bir şekilde bilgisayar bağlantısı oluşturulabilir (Başçiftçi ve Gündüz, 2019). Çalışmanın deneysel kısmında kullanılan Raspberry Pi' nin büyüklüğü bir kredi kartının büyüklüğü ile aynıdır. İngiltere'de aynı adlı şirketin geliştirmiş olduğu Raspberry Pi'nin amacı okullarda öğrencilere temel bilgisayar bilimlerini öğretmektir (Jain vd., 2014). Tercih edilmesinin nedenlerinden biri de düşük maliyetli olmasıdır.

Günümüzde güvenliği sağlamak amacıyla kullanılan sistemlerde, insanların tanınabilmesi ve bu şekilde tespit edilebilmesi için biyometrik güvenlik sistemleri daha çok kullanılır duruma gelmiştir. Bu nedenle yüz tanıma sistemleri ile insan yüzlerinin eşleştirilmesiyle sistemin daha hızlı çalışabilmesi oldukça önemlidir (İlkbahar ve Sungu, 2017). Yüz tanıma sistemleri birçok sahada farklı amaçlarla kullanılmaktadır. Bu sahalara örnek olarak, turnike geçişlerinin kontrolü, şirket ya da fabrika gibi yerlerde personellerin devamlılığını ölçen kontrol sistemleri verilebilir. Yüz tanıma sistemlerinin kullanımı her geçen gün artmaktadır. Bunun sebebi insanların rahatlığına zarar vermeden, düşük bir maliyet ile yüzleri doğruya en yakın şekilde ayırabiliyor olmasıdır (Heitmeyer, 2000). Elbette birtakım dezavantajları da bulunmaktadır. Yüzü taranacak kişinin kilo alıp vermesi ya da yüzünde meydana gelen yaralanmalar ve bu şekilde ortaya çıkan geometrik şekildeki bozulmalar, yüz tanımasının başarılı bir şekilde gerçekleşmesini olanaksız duruma getirmektedir (Varol ve Cebe, 2011).

Belirlenen senaryoya göre tasarlanan bir sistemin, ayrıca bir operatöre ihtiyacı olmadan istenilen çalışmaları gerçekleştirmesi otomasyon olarak tanımlanmaktadır (Harper, 2003). Ev içerisinde kullanılan teknolojik aletlerin insanların istekleri veya ihtiyaçları doğrultusunda uygulanabilmesi ve bunların denetlenebilmesi ise ev otomasyonu kavramını ortaya çıkarmaktadır. Farklı bir şekilde söylemek gerekirse ev otomasyonu, insanların mevcut hayatlarını kolaylaştıran, onlara emniyetli ve daha teknolojik bir ortam sağlayan sistemdir (Mersinoğlu, 2002). Birçok çalışmada uygulama yeri olarak ev kullanılmış ve bu evler uygulamaların işleyişlerine göre tasarlanmıştır. Bazı uygulamalarda prototip ev kullanılırken bazı uygulamalarda ise istenilen sayıda odaya sahip olan evler uygulama yeri olarak seçilmiştir. Yapılan bu çalışmaya benzeyen diğer çalışmalar incelediğinde, çalışmaların bir kısmında Raspberry Pi kullanıldığı görülmüştür. Jain ve ekibi yapmış oldukları çalışmada Raspberry Pi hakkında şunu ifade etmektedir; "kullanılan Raspberry Pi, Python programlama dili ile programlanabildiği gibi BBC Basic, C ve Perl programlama dilleri de kullanulabilmektedir" (Jain vd., 2014). Bahsi geçen bu programların kullanımı yapılan çalışmaların amacına bağlı olarak 
değişebilmektedir. Akıllı ev sistemlerinin sağlamış olduğu en büyük avantajlardan biri, farklı cihazların birbiri ile bağlantıda olarak sadece bir sistem üzerinden yönetilebiliyor olmasıdır. Ek olarak kullanıcı dünyanın neresinde olursa olsun webden ya da mobil cihazlar aracılığıyla uzaktan erişim imkânı sağlamaktadır (Öztürk ve Naimi, 2017). Mobil uygulamayla birlikte sistemin denetlediği cihazların iletişimde olabilmesini sağlamak amacıyla Bluetooth ve GSM teknolojisi kullanılabilir (Ahmad vd., 2011).

Birçok çalışmada yerel ağa erişmeden, GSM mimarisini kullanan ev aletleri için SMS tabanlı kontrol sistemi uygulanmıştır. Ancak bazı bölgelerde GSM alt yapısının yetersizliğinden kaynaklanan sorunlar nedeniyle çalışmaların işleyişinde aksaklıkların yaşanabildiği görülmüştür.

Geçmişteki çalışmalar kapsamlı bir şekilde incelendiğinde akıllı ev sistemleri oluşturulurken en önemli detayın bir internet bağlantısı olması gerektiği dikkat çekmektedir. Internet bağlantısı, yapılan çalışmaların sonucunda bir başarı elde edilmesi isteniyorsa bu çalışmaların olmazsa olmazı olarak adlandırılacak nitelikte büyük bir detaydır. Yapılan bu çalışmaların sonucunda yüzdelik olarak bir başarı durumu belirtilmemiştir. Ancak tasarlanan birçok çalışmada, uygulama yerleri üzerinde projeye dair tüm senaryolar gerçekleştirilmiştir. Aynı zamanda, otomasyon süreci ile ev otomasyonunun verimli ve güvenli bir şekilde başarıyla uygulandığına değinilmiştir. Bu uygulamalar sonucunda bir evin kontrolü istenilen şekilde başarıyla sağlanmıştır.

\section{KULLANILAN ARAÇLAR}

Akıllı ev sistemleri üzerine bir model önerisi yapılan bu çalışmada kullanılan donanımsal materyaller hakkında temel bilgiler bu bölümde yer almaktadır.

Çalışmada Raspberry Pi 3 Model B modülü kullanılmıştır. 1.2 Ghz, 4 çekirdekli 64 bit ARM Cortex-A53 işlemci birimini içeren Broadcom BCM2837 mikroişlemcisi üzerine kurulan Raspberry Pi 3 Model B modülü 1 GB belleğe sahip, 2 çekirdekli Videocore IV GPU grafik işlem birimine sahiptir. Üzerinde 4 adet USB 2.0 port, 10/100 Mbit/s destekli ethernet portu ve HDMI çıkışı bulunmaktadır. Çalışmadaki Raspberry Pi 3 kartı akıllı evde kullanılan sensörlerin verilerinin okunması, birimlere gerekli verilerin gönderilmesi (led yanması ya da kapanması) gibi işlemlerin yapıldığı en önemli ve kritik birim şeklinde açıklanabilir.

NodeMCU ESP8266, IoT tabanlı projelerin ayarlarını kolayca yapıp çalıştırmayı hedefleyen bir geliştirme kartıdır. Tek başına kullanılabilir ve ek olarak ayrı bir geliştirme kartı gerektirmez. I/O pinlerinin pwm, adc, IIC, 1 wire, uart gibi özellikleri bulunmaktadır. Kendi üzerinde anteni bulunmaktadır. Mikro usb ile kolayca bilgisayar bağlantısı sağlanabilir. Co2102 çipi sayesinde sürücü yüklemeye ihtiyaç duymaz. Arduino'nun yerini alabilecek kapasitede olan bu kart sayesinde kolaylıkla internete bağlanılabilir ve wifi ağlarını kolaylıkla 
görerek internet tabanlı projeler geliştirilebilir. Geliştirilen akıllı ev uygulaması prototip evde hayata geçirilirken, $5 \mathrm{~mm}$ olan Ledlere Arduino'nun voltajı tek başına yeterli olmadığ için, Arduino'ya ek olarak Raspberry Pi kullanılmıştır. Bu aşamada enerji ise powerbankten sağlanmıştır.

Pi Kamera Modülü, Raspberry Pi'yi destekleyen taşınabilir hafif bir kameradır. Görüntü işleme, yapay öğrenme veya gözetim projelerinde kullanılabilir. Raspberry Model A ve Model B'yi destekler. Akıllı ev ve güvenlik uygulamalarında oldukça popüler olan Pi Kamera Modülü için Python kütüphanesi de dahil olmak üzere birçok üçüncü taraf kütüphanesi oluşturulmuştur. Geliştirilen akıllı ev uygulamasında ise, Pi Kamera Modülü ile Telegram arasında bağlantı kurulmuştur. Pi kamera modülü kullanılarak LBP (Yerel İkili Örüntü Histogramları) algoritması ile yüz tanımaya ilişkin çalışmalar yapılmıştır. Buna ek olarak, ev sahibi Telegram üzerinden gönderdiği bir komut sayesinde evin dışından görüntü alabilmektedir. Bu şekilde ev girişinde güvenlik sağlanması amaçlanmıştır.

\section{YÖNTEM}

Yapılan çalışmadaki donanımsal materyaller, günümüzde popüler ve birçok uygulama ile entegre bir şekilde çalışıyor olan Telegram uygulamasıyla beraber kullanılmıştır.

Telegram uygulamasına verilen komutlar ile prototip evdeki ledlerin ve bahçe girişindeki kameranın kontrolü sağlanmıştır. Bu kontrolü gerçekleştirmek için Telegram uygulamasından verilen komutların bir kısmı, Görsel 1'de gösterilmiştir.
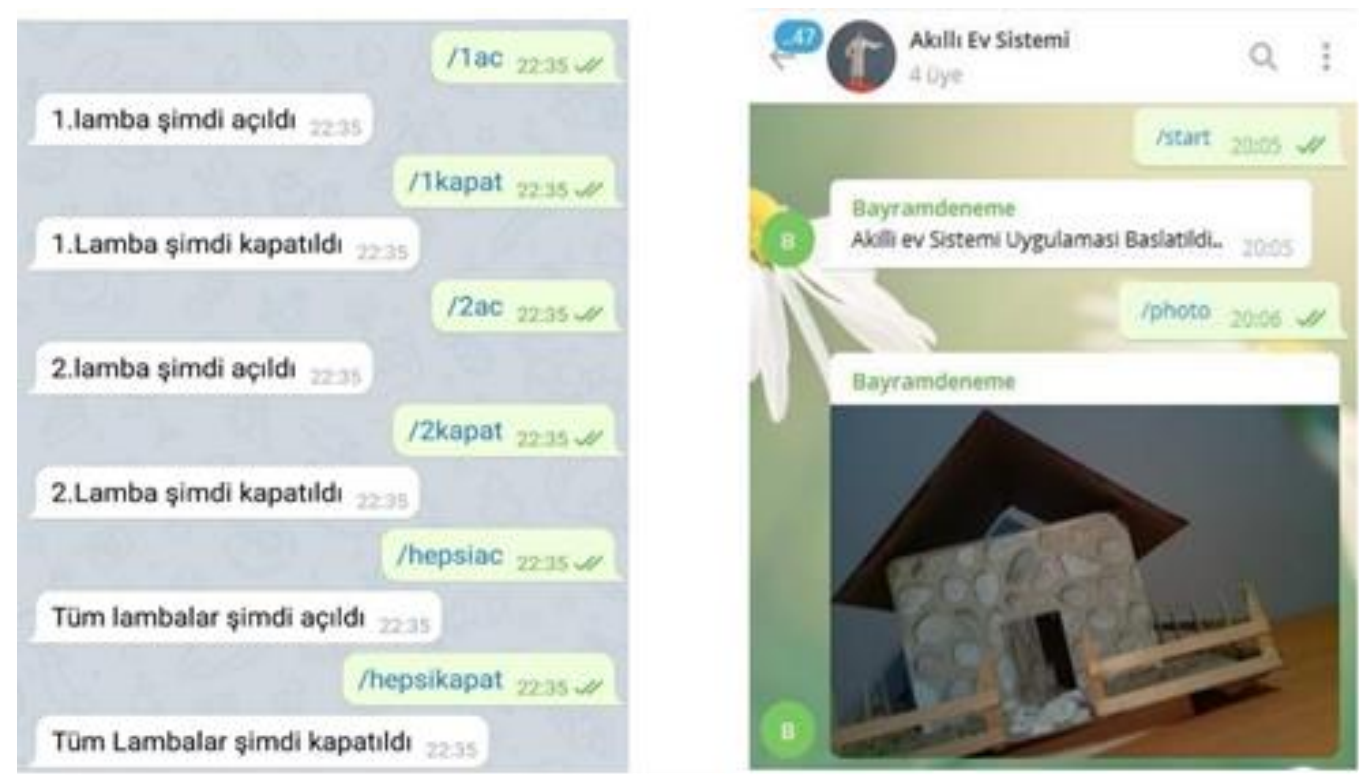

Görsel 1: Telegram Uygulamasından Verilen Komut Örneği

Veriyi çekebilmek için Telegram' in kendi hizmeti olan, botlara API hizmeti sağlayan Botfather kullanılmıştır. Bu sayede prototip ev ile Telegram arasında yetkilendirme izni sağlanmıştır. Botfather, tüm botları yöneten bir servistir. Yeni botlar oluşturulmasına ve mevcut olanlar için ayarların değiştirilmesine yardımcı olmaktadır. Telegram botu (akıllı ev 
sistemi botu) ve API, Botfather' dan bu çalışma için oluşturulan bota ait bir API anahtarı alınarak oluşturulmuştur. Alınan Bot API yazılıma aktarıldığında, aracı sunucu Telegram API ile tüm şifreleme ve iletişimi gerçekleştirmektedir. Bu sunucuyla, Telegram API' sinin basitleştirilmiş bir sürümünü sunan basit bir HTTPS arabirimi aracılığılyla iletişim kurulmaktadır. Bu arayüze Bot API denilmektedir. Akıllı ev sistemleri üzerine bir model önerisi olan bu çalışmada Raspberry Pi için Python programlama dili ile API ile iletişimi sağlayan Telepot kütüphanesi kullanılmıştır. Telegram, Raspberry Pi üzerinden Python'ın kütüphanesi olan Telepot ile Telegram API bilgisini kullanarak veri iletişimini sağlamaktadır. Arduino için C++ programlama dili ile API arası iletişimi sağlayan CTBot kütüphanesi kullanılmıştır. Telegram'ın Arduino kartıyla veri iletişimi bu şekilde sağlanmaktadır.

Akıllı ev kullanıcıları, Telegram uygulaması yardımıyla Raspberry Pi B+ ve Arduino (NodeMCU) kartlarıyla önceden tanımlanmış komut dizileri (lambaların durum kontrolü, kamera kontrolü gibi) çalıştırılmasını sağlanmaktadır. Kullanıcının komut dizileri içerisinde bulunan günlük dilde yazdığı basit özel ifadeler, Telegram Bot API yardımıyla chat ekranıla geliştirme kartlarında kullanılan kütüphane dosyaları arasında gerekli protokoller vasıtasıyla sağlanmaktadır. Bundan dolayı kullanıcı evinin içinde veya evinden uzakta olsa bile, ev içerisindeki modülleri (lamba, kamera kontrol modüllerini) rahatlıkla kontrol edebilmektedir.

Şekil 1'de gösterilen projeye ilişkin akış şemasında öncelikle, sistem başlatılır. Kullanıcının cihazında mevcut bir internet bağlantısı var ise cihazdan Telegram Chat uygulamasının seçilmesi gerekmektedir. Bu kısımda iki seçenek bulunmaktadır. 1. seçenek uygulamanın yapıldı̆̆ 1 prototip eve komut yollayabilmek için bot sohbet ekranına girilerek, istenilen komutun bu sohbet ekranı kısmında yazılması, 2. seçenek bot sohbet ekranına komut yazılmadan, Android'ın Google Asistan Servisi kullanılarak sesli komut verilmesidir. Bu sesli komut metne dönüşerek algılanacaktır. Her iki seçenekte de girilen komut tanımsız olursa ilk adıma geri dönülecektir.

Verilen komutlar tanımlı ise elektriksel olarak ifade yazılacak ve komut uygulanacaktır. Lamba haricinde girilen komut kamera ise Pi kamera modülü kullanıcının komutu verdiği an görüntüyü yakalayarak, kullanıcının komut verdiği bot ekranına gönderecektir. Girilen komut yazılımsal olarak sistemde tanımlı olmayan bir komut ise kullanıcı hata mesajıyla ve tanımlı olan komutu girmesi uyarısıyla karşılaşacaktır. 


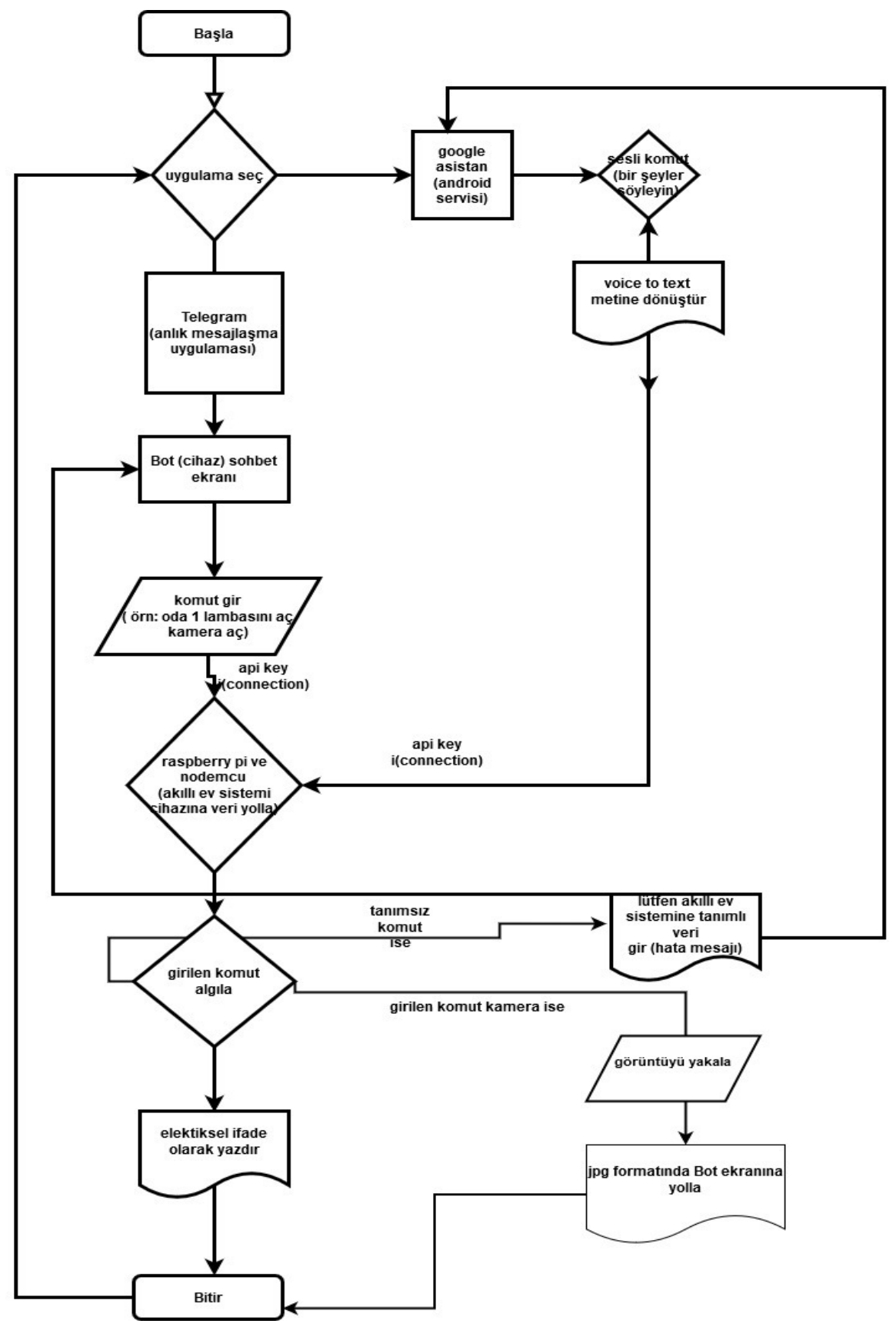

Şekil 1: Telegram Üzerinden Komut Verilmesine İlişkin Akış Diyagramı

Akıllı ev sistemi uygulamasında, ev girişinde güvenlik sağlamak amacıyla yüz tanıma sistemi kullanılmıştır. Yüz tanıma sistemlerinde birçok yöntem kullanılmaktadır. Bu yöntemlerden bazılarına TBA (Temel Bileşenler Analizi) ve BBA (Bağımsız Bileşenler Analizi) yöntemleri şeklinde örnek verilebilir. TBA birbiriyle ilişkili çok sayıda değişkeni kapsayan veri setinin boyutlarının, daha az boyuta indirgenmesini sağlayan bir dönüşüm tekniğidir. Boyutu az duruma getirirken veri içerisinde bulunan değişimleri mümkün olduğunca korur (Çilli, 2017). BBA ise değişken sayısı fazla olan istatiksel verilerin, kendilerine mahsus öğeler veya 
AJIT-e Bilişim Teknolojileri Online Dergisi

Academic Journal of Information Tecnology

2021 Spring/Bahar - Cilt/Vol: 12 - Sayı/Issue: 45

doi) 10.5824/ajite.2021.02.005.x

özelliklerinin bulunabilmesi amacıyla gerçekleştirilen bir analiz yöntemidir (Hyvärinen vd., 2001; Hyvärinen vd., 2009).

Bu çalışmada LBP (Yerel İkili Örüntü) algoritması kullanılarak yüz tanıma sisteminde uygulanmıştır. Bu yaklaşımın sağladığı avantajlar gri seviyeden bağımsızlığı, teorik olarak basitliği ve farklı 1şık şiddetlerinden fazla etkilenmemesidir (Ojala vd., 2002). Yapılan çalışmada Visual C++ ve Python dilleri ile ayrı ayrı tasarlanarak, openCV görüntü işleme kütüphanesinden yararlanılmıştır (İlkbahar ve Kara, 2017).

\subsection{YÜZ TANIMA YÖNTEMİ}

LBP (Yerel İkili Örüntü) yaklaşımı ilk olarak Ojala ve arkadaşları tarafından uygulanmıştır. Bu uygulama, bir görüntünün genelinden 3x3'lük parametrik olmayan bir çekirdek özeti çıkarılarak gerçekleştirilmiştir (Ojala vd., 1996). Şekil 2'de gösterildiği gibi görüntüyü oluşturan piksellerin her biri merkez piksel kabul edilir, komşu piksellerle karşılaştırılır. Bu karşılaştırma işleminde merkezden büyük olanlara "1", küçük olanlara ise “ 0 ” değeri verilerek ikilik sayı tabanında bir sayı elde edilir. Sonraki işlemde belirlenmiş katsayılar ile çarpılarak piksel değerleri toplanır. Bulunan toplam değer YïÖ kodu olarak isimlendirilir (Ojala vd., 2002).

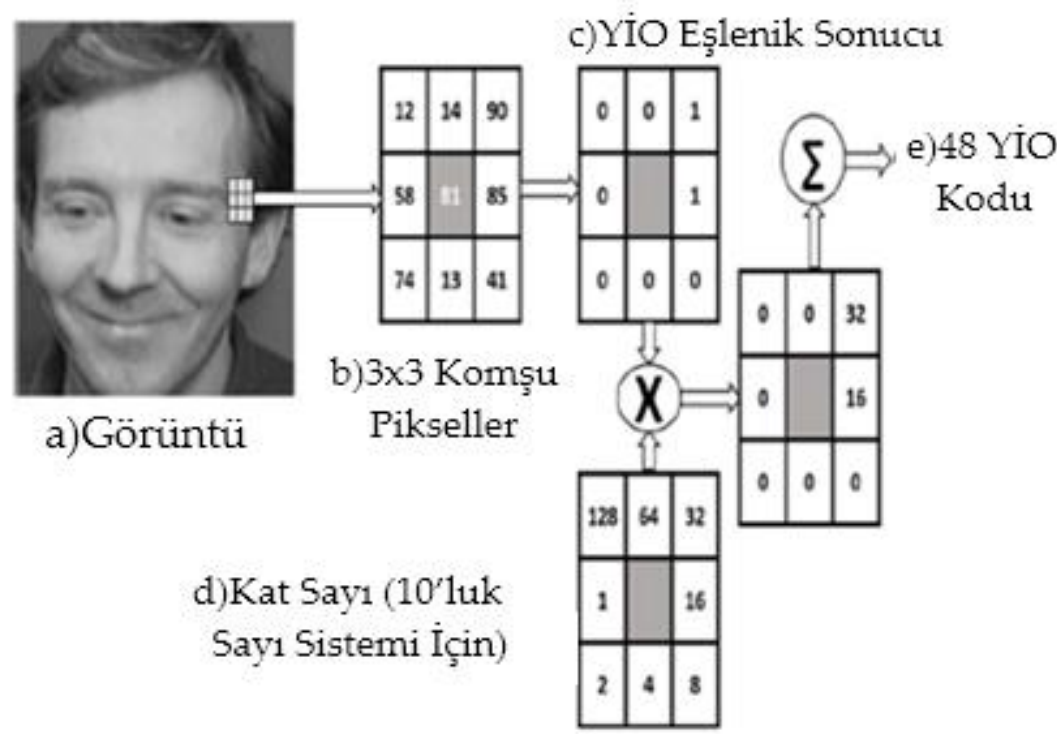

Şekil 2: Yerel İkili Örüntü Hesaplanış Örneği (İlkbahar ve Kara, 2017)

Şekil 3'de gösterilen kameradan yüz tanıma yöntemine ilişkin akış şemasında öncelikle sistem başlatılır ve ardından kamera sensörü çalıştırılır. Yüz tanıma sistemi tarafından anlık olarak belirlenen görüntü içerisinden yüz konumları algılanır. Algılanan yüz, insan yüzü ise görüntüde yüz konumları algılanıp öznitelikleri çıkarılan yüz ile önceden bir sınıflandırıcı algoritması yardımıyla sınıflandırılmış yüzler arasından yüz eşleştirilmesi yapılır. Eşleşen bir yüz ise evin 
kapısı 30 saniye boyunca açık kalır. Sonrasında ise yüz ile eşleşen isim Telegram yoluyla kullanıcıya bildirilir.

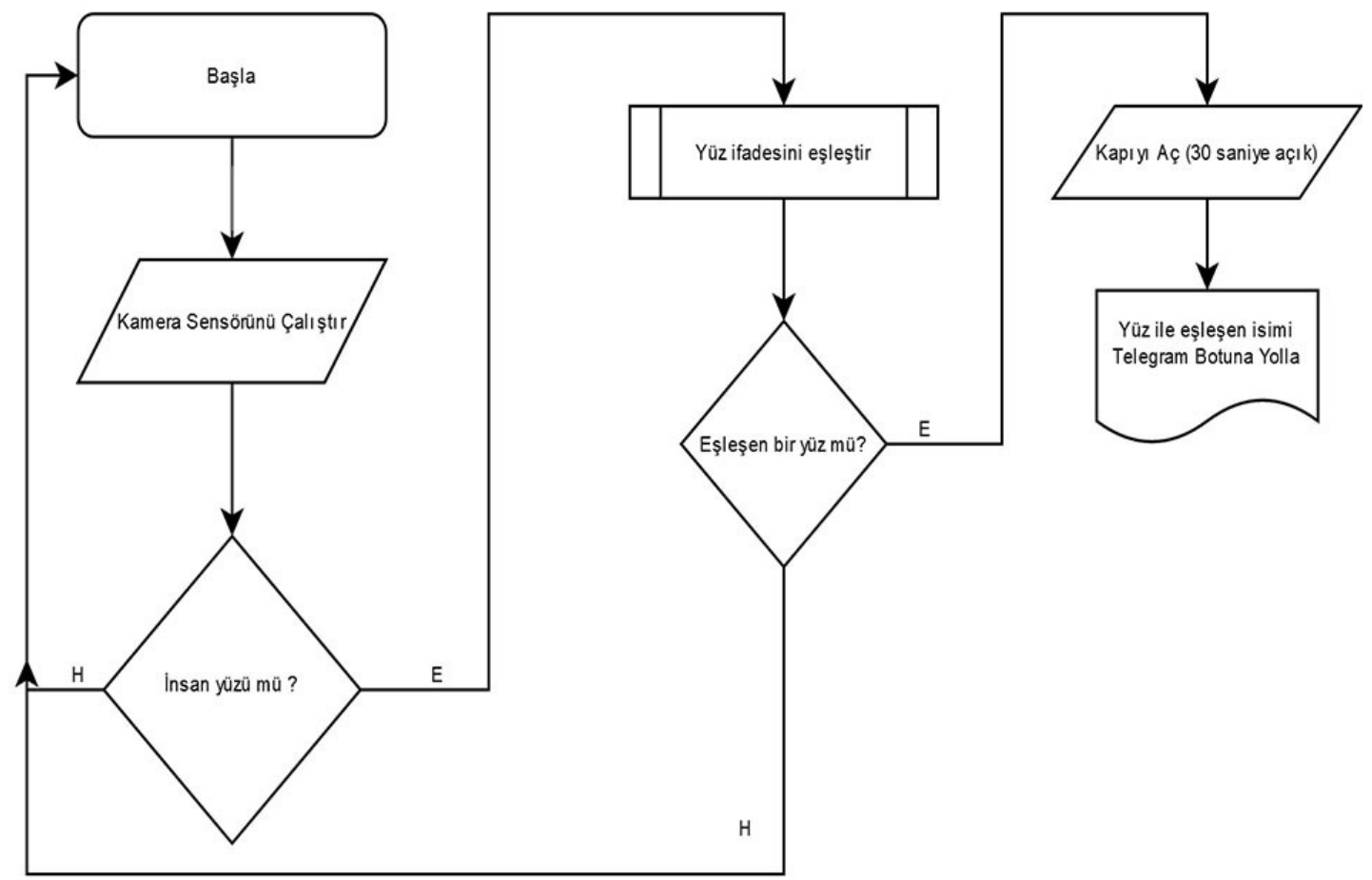

Şekil 3: Yüz Tanıma Sistemine İlişkin Akış Diyagramı

\section{DENEYLER}

Geçmişten bugüne, yapay zekâ uygulamaları çalışmalarının bir kısmı başarı ile sonlanırken diğer bir kısmı ise başarısız bir şekilde sonlanmaktadır. Yapılan çalışmaların başarısını ölçebilmek, gerçekleştirilen uygulamanın kullanıcıya yararını öğrenebilmek amacıyla çalışmalar sonlandırılmadan önce deneyler ve uygulama üzerinde testler gerçekleştirilmelidir. $\mathrm{Bu}$ deneyler ve testlerin amacl; tasarlanan sistemin her durumda çalışabilir olup olmadığını, hangi durumlarda hata verdiğini ve bağlantı aşamasında yaşanabilecek sorunları gözlemleyip sonuca ulaştırabilmektir. Akıllı ev sistemi tasarlanırken sürecin en başında, çalışmada kullanılan tüm modüllerin ve bunlarla bağlantılı olarak geliştirilen yazılımların başarıyla sonuç vermesi amaçlanmıştır. Sürecin sonlarına doğru yaklaşırken ise projenin uygulama kısmında ne denli başarılı olduğunu anlayabilmek ve projeyi istenilen seviyeye getirmek için ilk olarak projenin test öncesi durumu değerlendirilmiştir. Sonrasında ise var olan duruma göre test senaryoları belirlenmiştir.

$\mathrm{Bu}$ doğrultuda senaryolara göre gerçekleştirilen test adımları ve elde edilen sonuçlar rapor edilmiştir.

Test aşamasına geçmeden önce, Telegram uygulamasında Botun ve 3 kullanıcının bulunduğu, akıllı ev sistemindeki modülleri kontrol edebilmek üzere bir grup kurulmuştur. 3 
kullanıcının, hem prototip ev ve bahçede bulunan lambalar için hem de kamera modülü için istenilen sonuçları almaya yönelik verdiği komutlar çoğu zaman 1 dakikadan kısa sürede başarı ile gerçekleşirken bazen ise Arduino'dan kaynaklanan sorunlar nedeniyle sistem hata vermiş ve girilen komutlar başarısız sonuçlanmıştır.

Komutların çalıştığı anlarda lambaların açılmasıyla ilgili bir aksaklık yaşanmazken, kameranın görüntü alıp, görüntüyü Telegram uygulamasından geri bildirim olarak kullanıcıya ulaştırması, lamba komutunun verdiği sonuca oranla daha yavaş sürmektedir. Bu ise Raspberry'nin modeme olan uzaklığı ve bulunduğu ortamdaki internet hızından kaynaklanmaktadır. Akıllı ev sistemi projesinden istenilen verimin alınabilmesi için test aşamasına geçilmiş ve elde edilen sonuçlar tablolar halinde verilmiştir. Sistem üzerinde projeyi iyileştirmek üzere 100 deneme yapılarak elde edilen sonuçların başarı düzeylerinin ortalamaları alınmıştır.

Sistemin başlatılması için Telegramdaki bot üzerinden "/baslat" komutu girilmelidir. $\mathrm{Bu}$ komutun girilmesi ile sistem "Akıllı ev sistemleri başlatıldı" şeklinde geri bildirim vermektedir. Lambaların ve kameranın kontrolüne ilişkin çalışmalar ancak "/baslat" komutu girildikten sonra başlatılmaktadır. Evin içerisinde bulunan lamba, "1" olarak adlandırılmıştır. Lambanın açılması için "/1ac" komutu, kapanması için ise "/1kapat" komutu ile sisteme kaydedilmiştir. Sistem komutları gerçekleştirdikten sonra girilen komuta göre "1. Lamba şimdi açıldı" veya "1. Lamba şimdi kapatıldı" şeklinde geri bildirim vermektedir. Bahçede bulunan lamba ise, "2" olarak adlandırılmıştır. Açılması için "/2ac" komutu, kapanması için de "/2kapat" komutu ile sisteme kaydedilmiştir. Aynı şekilde lamba 2 için de sistem komutları gerçekleştirdikten sonra kullanıcıya geri bildirim vermektedir. Tüm lambaların kontrolünü sağlamak için ise "/hepsiac" ve "/hepsikapat" komutları girilebilmektedir. Sistem komutları gerçekleştirdikten sonra girilen komuta göre "Tüm lambalar şimdi açıldı" veya "Tüm lambalar şimdi kapatıldı" şeklinde kullanıcıya geri bildirim vermektedir. Sistemde kayıtlı olan komutun dışında benzer veya farklı bir komut yazıldığında, tek bir harf farklı dahi olsa sistem komutu algılamamakta ve çalışmamaktadır. Bu durumda sistem "Geçersiz Komut" şeklinde geri bildirim vermektedir. Tablo 1 ve Tablo 2'de komutların çıtısının ve kullanıcıya bildirilmesinin ne kadar sürede gerçekleştiği verilmiştir. Verilen komutların gerçekleşme süreleri kullanıcıların internet bağlantısı ile Raspberry ve Arduino'nun modeme olan uzaklığına bağlı olarak değişmektedir. 
Tablo 1: Lamba Komutlarının Gerçekleştirilme ve Çıktılarının Saniye Ortalamaları

\begin{tabular}{||l||c||}
\hline $\begin{array}{l}\text { Lamba1 ve Lamba2 için girilen komutlar kaç } \\
\text { saniyede başarıyla gerçekleştiriliyor? }\end{array}$ & 2,5 \\
\hline $\begin{array}{l}\text { Lamba1 ve Lamba2 için girilen komutların } \\
\text { sonucu kaç saniyede kullanıcıya bildiriliyor? }\end{array}$ & 2,8 \\
\hline $\begin{array}{l}\text { "hepsiac" komutu girildiğinde lambaların } \\
\text { hepsi kaç saniyede açılıyor? }\end{array}$ & 2,5 \\
\hline $\begin{array}{l}\text { "hepsiac" komutunu gerçekleştirdikten sonra } \\
\text { sonucu kaç saniyede kullanıcıya bildiriliyor? }\end{array}$ & 2,6 \\
\hline $\begin{array}{l}\text { "hepsikapat" komutu girildiğinde lambaların } \\
\text { hepsi kaç saniyede kapanıyor? }\end{array}$ & 2,3 \\
\hline $\begin{array}{l}\text { "hepsikapat” komutu gerçekleştirildikten } \\
\text { sonra sonucu kaç saniyede kullanıcıya } \\
\text { bildiriliyor? }\end{array}$ & 2,5 \\
\hline
\end{tabular}

Prototip evin giriş kapısında bulunan Pi kamera modülünün aktifleşmesi ve görüntü verebilmesi için kullanıcı tarafından Telegram uygulamasında sistemde tanımlanmış olan "/photo" komutu girilmektedir. Yapılan deneyler sırasında Bot tarafından "/photo" komutu girildiğinde bot kendi verdiği komuta cevap olarak görüntü gönderememiştir. Kullanıcı komutu kendi verirse görüntü alabilmekte ancak butona bastığında, verilen komutu Telegram kendi botu üzerinden verdiği için çalıştırmamaktadır. Bu nedenle kullanıcının dış cephe görüntüsü alması için kendisinin sisteme komut girmesi gerekli olmuştur. Bu konudaki çalışma, yazılımsal anlamda geliştirilmeye ihtiyaç duymaktadır.

Tablo 2: Kameranın Görüntüyü Gönderme Saniyesinin Ortalaması

\begin{tabular}{|l||c|}
\hline Kameranın aktifleşmesi için girilen komut & \\
sonucunda görüntü kaç saniye sonra kullanıcıya \\
gönderiliyor?
\end{tabular}

Yüz tanıma yönteminde, seçilen LBP (Yerel İkili Örüntü) algoritması Python programlama dili ile modellenerek çalışma hızlarının performans değerlendirilmesi yapılmıştır. Bu çalışmada Python programlama dilinde ORL veri seti tercih edilmiştir. ORL veri setinde bulunan 40 insan yüzünden, 10 farklı şekilde olmak üzere toplamda 400 (40x10) görüntü oluşturulmuştur. Her bireye ait olan 5 görüntü, eğitilmesi amacıyla geliştirilen sisteme verilmiştir. Toplamda 200 (40x5=200) görüntü, LBP (Yerel İkili Örüntü) algoritmasında test edilmiştir. Ortalama geçen zamanları saniye olarak Tablo 3.(a)'da gösterilmiştir. Eğitilmeyen görüntüler arasından her kişiye ait bir yüz görüntüsü seçilmiştir. Toplamda 40 (40x1) görüntüyü sistemin yaklaşık tanıma süresi Tablo 3.(b) de gösterilmiştir. Geliştirilen sistem, donanımsal olarak Intel i7 2.4 Ghz 4 çekirdekli işlemci ve işletim sistemi olarak da 64 
AJIT-e Bilişim Teknolojileri Online Dergisi

bit Windows 10 versiyonuna sahip bilgisayarda modellenmiştir. Ve deneyler yine bu bilgisayarda yapılmıştır (İlkbahar ve Kara, 2017).

Tablo 3: Performans Değerlendirmesi Sonuçları (İlkbahar, F., \& Kara, R., 2017)

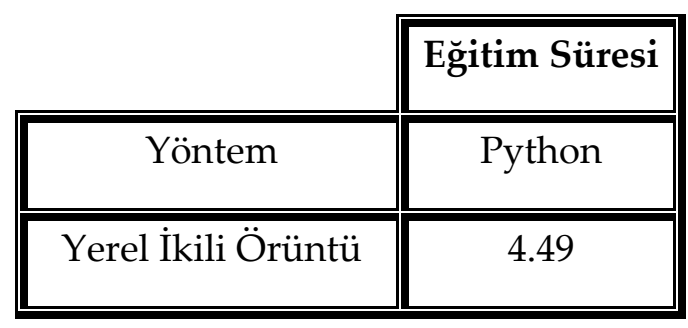

(a)

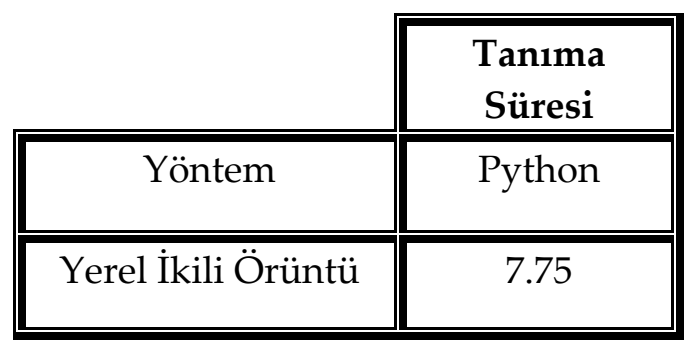

(b)

\section{SONUÇ}

Günlük yaşamlarında teknolojiyi daha etkin kullanmak isteyen insanlar için geliştirilen akıllı ev sistemleri uygulaması, güvenli ve konforlu bir yaşam standardı sunmayı amaçlamıştır. Bu amaç doğrultusunda, akıllı ev sistemleri prototipi yazılımsal ve donanımsal olarak gerçekleştirilmiştir. Geliştirilen sistem ile kullanıcılar, evlerinden uzakta olsalar bile Telegram uygulaması üzerinden ev içerisindeki lambanın ve kameranın kontrolünü gerçekleştirmektedir. Ayrıca geri bildirim de alabilmektedir. Uygulama üzerinde yapılan çalışmalar ve deneyler doğrultusunda kullanıcıların hem enerji tasarrufu yapabilecekleri hem de daha güvenli bir ortamda yaşayabilecekleri saptanmıştır. Tasarlanan akıllı ev sisteminin başarısını ve uygulanabilirliğini ölçmek amacıyla deneyler yapılmıştır. Kameranın evin dışından görüntü verebilmesi için Bot tarafından gerekli komut sisteme girilmiş ancak sistem kendi verdiği komuta karşılık geri bildirim gönderememiştir. Bu nedenle evin diş görüntüsünün alınabilmesi için kullanıcının komut vermesi gerekmektedir. Lambaların kontrolüne ilişkin yapılan çalışmaların ise deneyler sonucunda başarıyla gerçekleştiği görülmüştür. Python programlama dili kullanılarak yapılan yüz tanıma sisteminin performans değerlendirmesi sonucunda eğitim ve tanıma süresi hesaplanmıştır. 
Hesaplamaların sonucunda, eğitim süresi 4,49 saniye, tanıma süresi ise 7,75 saniye olarak belirlenmiştir.

Bu deneyler sonucunda kameradan evin dış görüntüsünü alabilmek veya lambaların kontrolüne ilişkin verilen komutların gerçekleşebilmesi, kullanıcıların o anki internet bağlantı hızına veya cihazların modeme olan uzaklığına bağlı olarak değişebilmektedir. Yapılan deneyler sırasında internet hızının iyi olmasından dolayı verilen komutlar, saniyeler içerisinde gerçekleşmiştir. Kullanıcıların internet altyapısının daha güçlü olmasıyla birlikte daha hızlı sonuçların elde edilebileceği düşünülmektedir.

Günümüzde akıllı evleri geliştirebilmek amacıyla birçok çalışma ve yeni fikir ortaya çıkmaktadır. Bu nedenle ilerleyen süreçlerde prototip ev üzerinde yapılan çalışmalar geliştirilebilir. Evde daha güvenli bir ortam oluşturabilmek amacıyla yangın veya su baskınlarını önleyebilmek için gerekli sensörler takılabilir. Deprem olması durumunda ilk titreşimleri algılayabilecek bir sensör ile kullanıcıya uyarı sinyalleri gönderilebilir. Evdeki sıcaklığı ölçebilen ve sıcaklığın belli değerlere ulaşmasıyla aktif duruma gelebilen bir fan sistemi kullanılabilir. Akıllı ev sistemi uygulamasında gerçekleştirilen çalışmalar ilerleyen süreçlerde insanların evlerinde ve işyerlerinde farklı fonksiyonlarda eklenerek uygulanabilir.

\section{KAYNAKÇA}

Ahmad, B. I., Yakubu, F., Bagiwa, M. A., \& Abdullahi, U. I. (2014). Remote Home Management: An Alternative for Working at Home While Away. arXiv:1403.3274 [cs]. http://arxiv.org/abs/1403.3274

Başçiftçi, F., \& Gündüz, K. A. (2019). Nesnelerin İnterneti Uyumlu Mikrodenetleyiciler Üzerine Bir Araştırma. Selçuk Üniversitesi Sosyal ve Teknik Araştırmalar Dergisi, 18, 62-71.

Çilli, M. (2007). İnsan Hareketlerinin Modellenmesi ve Benzeşiminde Temel Bileşenler Analizi Yönteminin Kullanılması. (Yayınlanmamış doktora tezi). Hacettepe Üniversitesi Sağlık Bilimleri Enstitüsü, Ankara.

Gökrem, L., Bozuklu, M. (2016). Nesnelerin İnterneti: Yapılan Çalışmalar ve Ülkemizdeki Mevcut Durum. Gaziosmanpaşa Bilimsel Araştırma Dergisi, (13), 47-68. Retrieved from https://dergipark.org.tr/tr/pub/gbad/issue/29709/319647

Harper, R. (Ed.). (2003). Inside the Smart Home. Springer-Verlag. https://doi.org/10.1007/b97527

Heitmeyer, R. (2000). Biometric Identification Promises Fast and Secure Processing of Airline Passengers. ICAO Journal., 55(9).

Hyvärinen, A., Hurri, J., \& Hoyer, P. O. (2009). Natural Image Statistics (C. 39). Springer London. https://doi.org/10.1007/978-1-84882-491-1

Hyvärinen, A., Karhunen, J., \& Oja, E. (2001). Independent Component Analysis. John Wiley \& Sons, Inc. https://doi.org/10.1002/0471221317 
AJIT-e Bilişim Teknolojileri Online Dergisi

Academic Journal of Information Tecnology

2021 Spring/Bahar - Cilt/Vol: 12 - Sayı/Issue: 45

10.5824/ajite.2021.02.005.x

İlkbahar, F., \& Kara, R. (2017). Performance analysis of face recognition algorithms. 2017 International Artificial Intelligence and Data Processing Symposium (IDAP), 1-5. https://doi.org/10.1109/IDAP.2017.8090338

İlkbahar, F., \& Sungu, E. (2020). Analysis of artificial intelligence technologies used in the covid-19 outbreak process. International Journal of Applied Mathematics Electronics and Computers, 154162. https://doi.org/10.18100/ijamec.800910

Jain, S., Vaibhav, A., \& Goyal, L. (2014). Raspberry Pi Based Interactive Home Automation System Through E-Mail. 2014 International Conference on Reliability Optimization and Information Technology (ICROIT), 277-280. https://doi.org/10.1109/ICROIT.2014.6798330

Li Jiang, Da-You Liu, \& Bo Yang. (2004). Smart home research. Proceedings of 2004 International Conference on Machine Learning and Cybernetics (IEEE Cat. No.04EX826), 2, 659-663. https://doi.org/10.1109/ICMLC.2004.1382266

Mersinoğlu, H. (2002). İletişim teknolojisi, Mimarlık Etkileşimi ve Akıllı Evler. (Yayınlanmamış yüksek lisans tezi). Yıldız Teknik Üniversitesi Fen Bilimleri Enstitüsü, İstanbul.

Mitchell, G. (2012). The Raspberry Pi Single-Board Computer Will Revolutionise Computer Science Teaching. Engineering \& Technology, 7(3), 26-26. https://doi.org/10.1049/et.2012.0300

Ojala, T., Pietikäinen, M., \& Harwood, D. (1996). A Comparative Study of Texture Measures with Classification Based on Featured Distributions. Pattern Recognition, 29(1), 51-59. https://doi.org/10.1016/0031-3203(95)00067-4

Ojala, T., Pietikainen, M., \& Maenpaa, T. (2002). Multiresolution Gray-Scale and Rotation Invariant Texture Classification With Local Binary Patterns. IEEE Transactions on Pattern Analysis and Machine Intelligence, 24(7), 971-987. https://doi.org/10.1109/TPAMI.2002.1017623

Öztürk, A., \& Naimi, S. (2017). Akilli Ev Sistemleriinde Kullanılan Yöntemlerin Farkları, Avantajları ve Dezavantajları. Istanbul Aydın Üniversitesi Dergisi, 9(4), 115-125. https://doi.org/10.17932/IAU.IAUD.13091352.2017.9/36.115-125

Stefanov, D. H., Bien, Z., \& Bang, W.-C. (2004). The Smart House for Older Persons and Persons with Physical Disabilities: Structure, Technology Arrangements, and Perspectives. IEEE Transactions on Neural Systems and Rehabilitation Engineering, 12(2), 228-250. https://doi.org/10.1109/TNSRE.2004.828423

Taştan, M. (2019). Nesnelerin İnterneti Tabanlı Akıllı Sulama ve Uzaktan Izleme Sistemi. Avrupa Bilim ve Teknoloji Dergisi, 15, 229-236. https://doi.org/10.31590/ejosat.525149

Varol, A., \& Cebe, B. (2011). Yüz Tanıma Algoritmaları. 5th International Computer \& Instructional Technologies Symposium, Elazı $\breve{g}$.

Yiqin, L., Fang, F., \& Wei, L. (2009). Home Networking and Control Based on Upnp: An Implementation. 2009 Second International Workshop on Computer Science and Engineering, 2, 385389. https://doi.org/10.1109/WCSE.2009.836 